obviously puts an enormous strain on those who are in post. For the last two years we have been trying to fill our two vacant Consultant posts; we have not had any applicants with MRCPsych, but one or two Senior Registrars with only the DPM applied and so were rejected by the Committee.

Now, if the recommendation is strictly adhered to (and I believe it will be), I see no hope of full recruit ment for Consultant posts in mental handicap hospitals being achieved, and thus the upgrading of patients' care and treatment will be seriously jeopardized. Unless the College finds an alternative way of staffing mental handicap hospitals, there can be no improvement in the standard of care, therefore defeating the College's role.

The only alternative I can suggest is the practice of 'Comprehensive Psychiatry'. In this, the discriminating terms such as General Psychiatry, Mental Handicap, etc are abolished. A Consultant Psychiatrist who has adequate clinical knowledge and training should be able to treat any psychiatric patient, whether or not some element of intellectual deficit is involved. Also, it is not uncommon to find some chronic schizophrenic after years of treatment being branded 'subnormal' and sent to a long-stay ward of a large mentid handicap hospital on a par with any general psychiatry hospital. If we abolish this discriminatory terminology, then the staff recruitment prospects will be better and a higher standard will be maintained. Otherwise I see no hope of an improvement in the mental handicap hospital, which will remain a sore point to the College.

UTPAL J. DEY

Brockhall Hospital, Consultant Psychiatrist

Blackburn.

\section{THE MRCPsych EXAMINATION}

DeAR SiR,

We would like to respond to the points raised by Dr. Srinivasan in his letter, (Bulletin, July 1979, p 125).

The best criticism of the APIT Exam Workshop is not, as Dr. Srinivasan suggests, that it 'adds to the confusion', but that APIT has joined the bandwagon by helping candidates to pass an examination it has always opposed! In fact, the Workshop was designed to help those candidates who are known to be clinically competent but who repeatedly fail the exam because of faulty technique. We would refer to a letter in the APIT Newsletter (April, 1979) from a candidate who attributed her success at the third attempt partly to our Workshop where she learned (1) a logical system of formulation; (2) the need to leave adequate time within the hour to think and write it out; (3) that the examiners would not demand a single firm diagnosis; and (4) that she should not make it such hard work for the examiners to 'extract' information from her. This candidate also comments on her experience at different centres, and it is in response to all these factors that we wrote the letter requesting clarification and standardized practices.

Inevitably, the Workshop also attracts a proportion of candidates who are not clinically competent and who are 'confused'. The problem with the MRCPsych exam is that it simply fails such doctors and provides no impetus for improvement in their basic training. This has always been APIT's criticism. How can a trainee spend three years in an 'Approved' post, be considered ready to take the MRCPsych exam by his clinical tutor, and yet not know how to record the mental state examination?

Dr. Srinivasan quotes a pass rate of about $50 \%$ in the MRCPsych exam last year as evidence that one should not be pessimistic. If this is a reliable measure of the standard of clinical practice it does not suit his argument well, as the pass rate has fallen over the years, not risen $^{1}$. He also fails to point out that for overseas trainees the pass rate is very much lower than this, which is probably a reflection of the fact that these doctors are much more likely than their UK counterparts to work in 'peripheral' hospitals where even Dr Srinivasan admits 'there is room for improvement' in the training provided.

Our recent survey of training in one Region supports this view as 37 out of 43 trainees at the undergraduate teaching hospitals had been specifically taught how to record a mental state examination, whereas only 23 out of 46 at regional hospitals had been so taught. The figures for the teaching of formulation are lower and similarly disparate, and those for the teaching of interview skills pathetic. It is not, therefore, surprising that trainees in these hospitals often regard the MRCPsych exam with enormous pessimism and desperation. They become totally preoccupied during their first year with the need to pass the Part I MCQ hurdle, and this detracts from the essential task of acquiring basic clinical skills. The importance of 'clarification of examination protocols' should not therefore be underestimated, and if, for example, a candidate knew he would be given 10 minutes specifically to write a formulation in the exam, he would presumably be more insistent that his consultant teach him exactly what this involves and allow him to practise this skill each week in his routine work. Any hospital which does not offer this facility should not be considered suitable for training, and the standard of clinical practice may indeed be questioned. 
Finally, is criticism of the MRCPsych exam by trainees such a bad thing? Has it already become a sacred cow that should be revered? Some young trainees see it simply as a hurdle to be crossed and forgotten, but APIT regards a periodic re-evaluation of the effect that the exam has on training as being of great importance. Fortunately, senior members of the College are not complacent either and have responded to our letter by organizing another examination forum. Of course, clinical tutors could arrange mock examinations for their candidates, as Dr Srinivasan suggests (this is a well recognized procedure in preparation for the MRCP exam) but it is precisely their failure to do so that led APIT, an organization responsive to trainees' needs, to take the initiative. As to 'regional scientific meetings geared solely to the trainees' needs', it is worth noting that five such meetings have already been held in three Regions. Each was organized by a member of APIT who recognized the shortcomings of the local training and made a constructive attempt to improve it.

Francis Creed

RI CHARd Williams on behalf of $A P I T$

Department of Psychiatry,

London Hospital,

Whitechapel.

REFERENCE

'News and Notes, March 1977, p 11.

\section{DIAGNOSTIC FORMULATION IN THE MRCPSYCh EXAMINATION}

DeAR SIR,

There have recently been two contributions to the debate about the expectations regarding diagnostic formulation in the MRCPsych clinical. The first, on behalf of APIT (Bulletin, April 1979, p 67) precipitated the second which appeared in 'The Scribe's Column' (Bulletin, June 1979, pp 108-9). I should like to add a personal contribution to the discussion. I myself passed the MRCPsych examination in 1977, but I have witnessed several colleagues fail to surmount this obstacle at the first attempt, although knowing that their standard of clinical practice was high.

It seems to me that there are two arguments against providing candidates with explicit guidelines in preparing a diagnostic formulation for the examiners. The first is the 'spoon-feeding' argument. According to this view any candidate aspiring to obtain higher qualification should be able to marshall his facts so as to satisfy any reasonable examiner; to provide a formal scheme for presentation is to 'spoon-feed' less able candidates and possibly to restrict the more able. The second argument is that to force a young psychiatrist to formulate a case in a particular way may have some undue influence on the development of his everyday practice; furthermore, that the 'formulation' thus imposed will be a compromise devised for the examination and thus not suited for ordinary clinical usage. There is a third possible a:gument which is that the members of the Examination Committee could not agree amongst themselves as to what form such guidelines should take. I cannot believe that this is true and I shall thus confine myself to arguments on the first two points.

The 'spoon-feeding' argument really falls down when one realizes that it is not allowed to intrude into the design of the written papers. In the Multiple Choice Paper one is told precisely how to signify one's answers. Even in the essay paper one has a restricted choice of questions, and every good candidate knows that the form of the question dictates the form of the answer. There is still scope for individuality, but the expectations of the question are usually sufficiently restricted to allow the marker to make some attempt at comparison with his ideal answer. Neither can it be claimed that such restrictions in written papers are justified in that written accounts are a lesser skill in everyday practice than clinical assessment; the two are inseparable in providing a proper psychiatric service. If it is correct, as I believe it is, that written examinations should have carefully predetermined expectations as to form of answer, then it must be correct for clinical examinations to be treated in the same way.

What can be said about the possible problem of a scheme devised for 'diagnostic formulation' in examinations being used by trainees in the inappropriate setting of day to day clinical duties? It seems to me that such a scheme is unlikely to be so attractive as to beguile the unwary into applying it indiscriminately. Even if I am wrong in this belief, little practical harm would be done. It has been shown that the relationship between diagnosis and treatment decision is not as strong as might be expected (Bannister et al, 1964; Williams, 1979). In an unpublished retrospective survey of 136 patients with symptoms or signs of depression, I obtained data supporting the assertion of the quoted papers; also my findings lent support to the recommendation in the latter paper that the problem-oriented approach is a useful addition to more traditional formulations of diagnosis. 